\title{
Restructuring Educational Institutions for Growth in the Fourth Industrial Revolution (4IR): A Systematic Review
}

\author{
https://doi.org/10.3991/ijet.v15i03.11849 \\ Byabazaire Yusuf ${ }^{(\bowtie)}$ \\ Universiti Utara Malaysia, Sintok Kedah, Malaysia \\ byabazaire@uum.edu.my \\ Lynne Masel Walters \\ Texas A\&M University, Texas, United States \\ Siti Nazuar Sailin \\ Universiti Utara Malaysia, Sintok Kedah, Malaysia
}

\begin{abstract}
Industrial Revolutions basically have transformed human lives. We have gone from hand production to mechanized production into computerization or automation of concepts into products (Fourth Industrial Revolution (4IR)). However, 4IR urges the process of transferring data from digital domains and offline reality via interconnected systems to improve lives. The technologies in 4IR enter into varying areas, such as the economy, medicine and education. Educational institutions have contributed greatly to reshaping future technologies by being the test laboratories for innovations. In the meanwhile, there is an immense need for looking beyond the traditional educational approach. This can be achieved by strategically employing the trending technologies to prepare students and educators with the right kind of knowledge and set of skills. It is imperative to ask questions about how the delivery of education will be undertaken and how educational institutions will be restructured by the 4IR to prepare students for the challenges ahead.
\end{abstract}

Keywords - Fourth Industrial Revolution, Educational Institution, technology, student and workforce

\section{Introduction}

Science and Technology (S\&T) is are essential part of our lives today, and few can imagine living without them. More importantly, Science and Technology have helped mankind to achieve a holistic approach that transcends existing human limitations and improves conditions for work, learning, aging, and physical and cognitive wellness[1]. This transformation has brought about a shift in wealth and knowledge, thereby enabling knowledge sharing and decision making among individuals as well as organisations [2].

To thrive in these times, we must prepare the future workforce to understand, learn and utilize S\&T applications in academics [3]. Educational institutions are laboratories for research and innovation in which technologies from the Fourth Industrial 
Revolution (4IR) are used to improve human lives. Before discussing the significance of 4IR technologies in educational institutions, it is imperative to provide context, to give a brief historical background of Industrial Revolutions and how they influenced the educational system [4].

In 1790, the First Industrial Revolution started with the invention of steam engine used by farmers for agricultural and feudal society for manufacturing. The Second Industrial Revolution started in 1900 with the invention of the internal combustion engine, leading to an era of electricity and oil fuelled machines. The Third Industrial Revolution began in 1960 with the invention of electronics and IT to automate production.

The Fourth generation (4IR) started in the early 2000s. It involves computer generated products, such as 3D printing technology, intelligent agents, biotechnologies and nano materials. The technology in 4IR creates the future, and it should make things easier for people economically. Social and educational changes propelled by this and previous industrial revolutions provide basic transformations in higher education curriculum (See Table 1).

Table 1. Educational Response to Industrial revolution Source [3]

\begin{tabular}{|c|c|c|}
\hline Industrial revolution & Period & The description of educational curriculum \\
\hline First Generation & $\begin{array}{l}\text { In the early } \\
1800 \mathrm{~s}\end{array}$ & $\begin{array}{l}\text { This Industrial Revolution was originally intended to lead educational } \\
\text { institutions into what is known as a New Education. It is a vision for a } \\
\text { whole new kind of educational curriculum offering various degree op- } \\
\text { tions, as well as introducing novel educational programs. }\end{array}$ \\
\hline Second Generation & $\begin{array}{l}1860 \text { to } \\
1900\end{array}$ & $\begin{array}{l}\text { Second Industrial Revolution was intended to make educational } \\
\text { opportunity accessible for the industrial classes "sons of toil." It was } \\
\text { intended to give birth to a "new economy" and to enable education } \\
\text { that is "created for a steady stream of newly trained technicians and } \\
\text { engineers trained in the practical avocations of life." }\end{array}$ \\
\hline Third Generation & $\begin{array}{l}1980 \mathrm{~s} \text { to } \\
1990 \mathrm{~s}\end{array}$ & $\begin{array}{l}\text { The Third Industrial Revolution is fashioned around web-based } \\
\text { technologies. This basically involves the internetwork of distributed } \\
\text { systems for easy online access to information and data. One of the } \\
\text { biggest ripples from this era is the migration towards online education } \\
\text { In the year 2012, massive open online courses are expected to com- } \\
\text { pletely displace the traditional on-site educational system, designated } \\
\text { as the "Year of the MOOC.” This extended access to university } \\
\text { education to many people who previously were unable to take courses } \\
\text { of interest or attend universities of choice. The Third Industrial } \\
\text { Revolution has brought educators to an environment where access to } \\
\text { information is immediate and free, shifting the focus toward active } \\
\text { learning pedagogies that place a premium on collaboration within } \\
\text { diverse teams in a project-based and peer learning environment. }\end{array}$ \\
\hline Fourth Generation & $\begin{array}{l}\text { 2000s till } \\
\text { date }\end{array}$ & $\begin{array}{l}\text { The } 4^{\text {th }} \text { Industrial Revolution often is described as the compounding } \\
\text { product and multiple integrating effects of "exponential technologies," } \\
\text { like artificial intelligence, computer networking technology, biotech- } \\
\text { nologies and nanomaterials. The best-known exponential technology } \\
\text { is an "increase in computer power and decreasing cost in storage." } \\
\text { However, substantial amendment will be made to the educational cur- } \\
\text { riculum, allowing students to rapidly develop in emerging disciplines } \\
\text { like artificial intelligence, robotics, genomics, data science, and nano- } \\
\text { materials. 4IR STEM curriculum would still have to reconsider the } \\
\text { traditional curriculum, like biology, chemistry, and physics but in a } \\
\text { different sphere or with a new perspective. }\end{array}$ \\
\hline
\end{tabular}


The current Industrial Revolution puts a premium on adaptability in learning and thinking. This implies that the shelf life of the present-day educational skillset has become increasingly short, requiring the future workforce in our classrooms to update their knowledge and proficiencies to meet the demands of new technologies and industries [1], [4]. Transforming educational institutions for growth in the 4IR is not possible without the necessary infrastructure. This means advanced technology (internet, highpowered machines), data (unstructured, structured, stream, Big, audio, image, text and sensor), institutional configuration (curriculum) and skilled experts (field/practical, non-formal, formal) [3], [5], [6], [7].

The disruptive 4IR technologies are powered by the 'Internet of Things'(IOT),

Robotics, Nanotechnology, Genomics, Artificial Intelligence, Virtual Reality (VR), Cloud, Edge, Fog computing and other technologies as shown in Figure 1.

\section{CHARACTERISTICS OF 4IR}

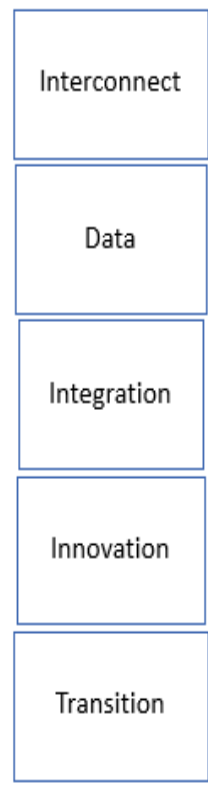

COMPONENTS OF $4 I R$

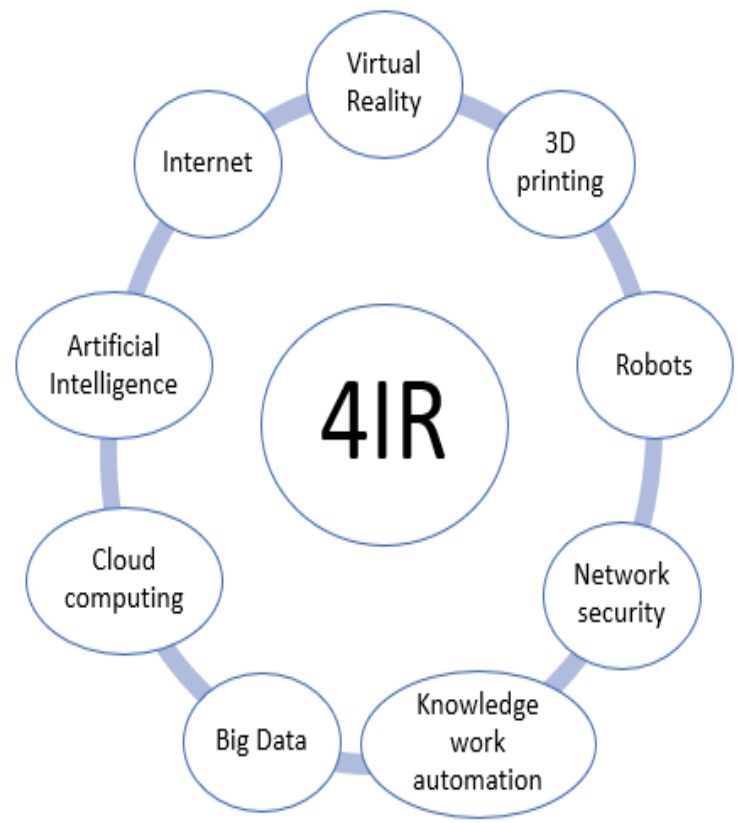

Fig. 1. Characteristics and Components of 4IR technology source [8]

Combining 4IR technologies in educational institutions will bridge the gap between humanities and social sciences by strengthening knowledge sharing processes as they transition from task-based to human-centred approach. Many interdisciplinary fields of study will be required for the efficient convergence of 4IR technologies in educational institutions [9], [10]. 
A better educational requirement within 4IR would be to incorporate a strong overlay of ethical, intercultural and critical thinking to enable thoughtful application of the exponentially developing technologies. A well planned 4IR form in educational institutions will ensure a knowledgeable workforce that will graduate into a world they can help restructure with the right skills and wisdom. Students and graduates with 4IR skills can create a culture which improves the sustainability of future technologies. As regards better skills requirement in educational institutions for 4IR, Figure 2. gives an elaborate illustration of what will be needed [11].

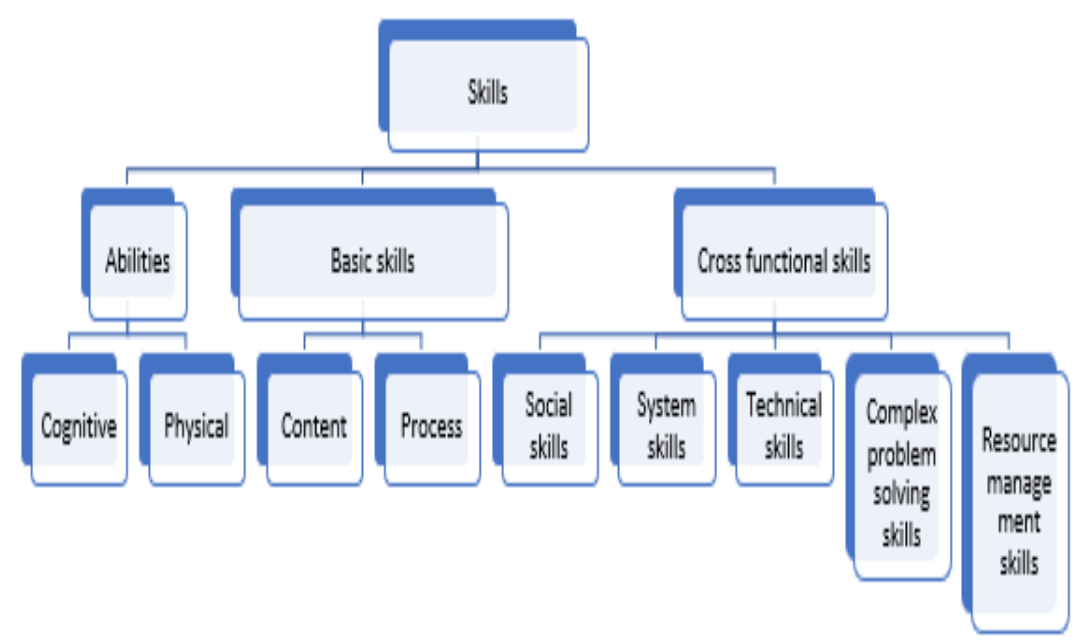

Fig. 2. Core skills needed in 4IR source [11]

Figure 2. illustrates the list of minimum skills required by future worker to meet the challenges encountered with the technologies in 4IR. These are:

- Abilities: This is the capacity to act mentally and physically Cognitive abilities require having a flexible mind-set, logical reasoning, problem sensitivity, creativity, and mathematical reasoning. Physical ability requires having mental and physical alertness, as well as manual dexterity and precision.

- Basic skills: This skillset can be differentiated into content skill and process skill. Content skills require active learning, ICT literacy, reading comprehension, oral and written expression. Process skills require active listening, critical thinking, monitoring self and others.

- Cross-functional skills: The cross functional skillset cuts across other skillsets dimensions, like social skills, technical skills, system skills, complex problem-solving skills, and resource management skills. 
Success with 4IR heavily depends on an educational skillset that fosters direct cooperation between man and machines. Educational institutions must face the hurdles of providing educational settings for this revolution [3], [10].

This paper focuses on the need for strengthening educational institutions, as well as tackling the challenges of Industry 4.0 (Section II.A) delivers an overview about convergence of educational system with 4IR, (Section II.B) explains the innovative elements of the educational curriculum (Section II.C) emphasizes the orchestration of realtime classrooms to support teaching and learning. The Sections III addresses the challenges of restructuring educational institutions to meet up with 4IR. The paper ends with conclusions and an outlook on further research (Section IV).

\section{Relevant Literature}

\subsection{Convergence of educational system with 4IR}

Creating a successful workforce in the era of 4IR presents some questions about needed qualifications. The new generation of workers must have the required skills and methods for 4IR. This is not limit to the educational context; cross-functional skills also are needed. This generation, also known as "Working World 4.0," will need altered competencies [12]. For instance, development of cyber-physical systems will require professionals from multidisciplinary fields, like computer networking and computer science. These experts also will collaborate with experts in other fields in a harmonized context, based on achieving targeted goals. Goal-based innovations are aimed at revolutionizing and restructuring educational institutions [13]. Moreover, it will be challenging to solve open-ended problems, within changing teams, to successfully orchestrate research and development of an idea or product. These challenges include:

- The appearance of new generation of students with constant distractions from varying sources

- The rewiring of students' brains due to a reduced attention span

- The likelihood that science and technology are outpacing teaching and learning

- The facts that schools are not helpful in suggesting or choosing career paths for the future workers [8].

For these reasons, workspaces are fully virtualized, or remotely controlled for collaborations and research by well-skilled investigators, students and experts [3], [5]. It is undoubtedly true that the autonomous organized value chain creates a substantial task for human labour. intelligent agents, machines and data provoke the need to restructure the skill competence of Workforce 4.0 [12]. Social and meta-cognitive skills are in demand through the interlinking of education and competence measurement. As a

result, being an expert on a subject is in less demand than the ability to think Globally across different disciplines with a holistic understanding of a domain [10], [14].

Thus, knowledge transfer from educational institutions is massively changing the competence level of the Workforce 4.0. However, qualification from knowledge gained 
in non-formal learning scenarios is now of utmost importance [14]. This indicates that both formal and informal educational structure should be embraced in every institution for knowledge sharing purposes. Nonetheless, knowledge cannot be shared when there are no fundamental technological tools available to transfer information [15], [16]. Innovative elements need to be added to the traditional educational curriculum to meet the growing demands of the labour market. All these requirements must be accessed by the future workforce and possessed by educational institutions for the transformation of teaching for the coming generations. These requirements are inter-related with the future work environment.

\subsection{Innovative elements to the educational curriculum}

4IR needs an educational design framework that would have a strong overlay of critical thinking on exponentially growing technologies. Graduate students at any 4IR educational institution should possess the abilities and skills to develop a culture which, thoughtfully and responsibly, improves the sustainability of advanced technology [17].

A new framework was developed to respond to the volatility of labour market. This framework shifts emphasis from the routine task of the traditional academic curriculum to more creative activities. This framework is known as Career and Technical Education (CTE) [18]. The importance and role of CTE is based on previous study [19], which speculated that three mechanisms of CTE courses generally may affect college completion or dropout (without considering the importance and role of timing). The first mechanism is skill building, CTE courses stress the need of cognitive thinking for problem solving purposes. This is intended to allow students to gain a wider range of skills as they develop knowledge within CTE courses. The knowledge can be applied in other disciplines and beyond the borders of educational institutions [20], [21].

The second CTE mechanism is engagement. CTE courses focus heavily on educationally engaging students better than they are in traditional courses, with content that is mostly theoretical or abstract in nature [19]. As CTE courses focus on the relationship between traditional educational content and its career-based applications, academic materials are likely to be more engaging through applied contextual learning and handson experiences. As such, the design of CTE courses boost student motivation, which may tend to decrease dropout rates [22]. Therefore, it may be possible to increase the graduation rate, particularly given the underlying theory of action linking CTE in high school to both college and career opportunities [18].

The third mechanism is real-world practical relevance. CTE courses have the potential to transform student knowledge and skills since it is the nexus of both practical relevance and traditional content of educational system.

According to Bishop and Mane [23], if students were offered the opportunity to prepare for their career during upper-secondary school, their classroom attendance would increase. This will directly improve the job potential of high school graduates whether they complete postsecondary education or not. When educational institutions provide training to students, the barrier to entering into skilled occupations will drop, the supply of skilled workers will increase, the cost of employing skilled workers will fall, and the expanded use of technology will be facilitated [24]. 
Models of shared leadership between two parties can be an effective means of displaying 21 st century skills for students entering the workforce after graduating from high school. Effective shared leadership can result in higher levels of productivity and increased teacher effectiveness. Further, the implementation of shared leadership can increase participants' perceived levels of job satisfaction through their impact on the decision-making process. As shared leadership participants utilize characteristics of 21 st century skills, the implementation of this model could be beneficial to students, and help them graduate high school with high demand skills, such as collaboration and communication among teammates.

Data were utilized by an exemplary CTE centre to compare its students' experiences with the traditional high school experience using quantitative approach. In interviews both high level and average students favourably commented on their CTE experience. However, they commented negatively on their traditional high school experience. Four main themes surfaced in their responses: relevant content in an applied setting, caring teachers, students with similar interests, autonomy and effectiveness [25].

Preparing all students for career-college readiness can be achieved with CTE as postulated by Saeger [26], who noted the need for further development and alignment of a comprehensive curriculum with core academics, and technical, job specific and employability skills. CTE must be ready to play an important role in the $\mathrm{K}-12$ reforms in order to maximize its full potential in the educational system. This will serve as a preparatory cohesive pathway for students entering post-secondary education and workforce. CTE can provide the leadership that will prepare students to be successful in today's globally competitive high-skills, high-demand work force.

In the study performed by [18], high school CTE courses were linked to increased chances of on-time student graduation and reduced or lower chances of school dropout. This is especially true when courses were later taken in high school. Little evidence arose that CTE course taking boosts college-going behaviours. The implications speak to the role of timing CTE course taking, specifically on end of high school outcomes.

CTE proponents believe that its major strength lies in the ability to promote career readiness skills for the growing workforce. It is evident that the short-term assignments and the flexible nature of work are key factors to address within 4IR education [23], [27].

Another innovative initiative exploring 4IR education is the Stanford2025 project, which envisions several mechanisms whereby students can extend their education over longer time frames. Stanford 2025 consists of four models which allow students to perfectly fit into the technological shift within the 4IR. This is further explained in Table 2.0 . 
Table 2. Stanford2025 project Source [3]

\begin{tabular}{|c|c|c|}
\hline Models & description & Presaged achievements \\
\hline $\begin{array}{l}\text { "open loop uni- } \\
\text { versity" }\end{array}$ & $\begin{array}{l}\text { Students will be able to experience six } \\
\text { years of higher education for their entire } \\
\text { adult life. This will allow them to have a } \\
\text { mix of life experiences by providing value } \\
\text { in return to the campus as an expert practi- } \\
\text { tioner with several intervals. This will ena- } \\
\text { ble students to refresh or update their } \\
\text { skills, while interacting with the campus } \\
\text { or educational institutions [28]. }\end{array}$ & $\begin{array}{l}\text { Time of early-career student is properly } \\
\text { managed. Time spent learning in and on- } \\
\text { campus is wisely spent on greater impact. It } \\
\text { complements their legitimate learning } \\
\text { patterns. It formulates a medium where older } \\
\text { adults pivot careers with academics, thereby } \\
\text { reconnecting to meaningful context in life or } \\
\text { career. } \\
\text { Creating an on-ramp mix of students from } \\
\text { traditionally underrepresented traditional } \\
\text { populations to have better access to other } \\
\text { skills by overcoming their disadvantaged } \\
\text { circumstances. } \\
\text { Operational infrastructure is developed to han- } \\
\text { dle the shift of on-campus population. }\end{array}$ \\
\hline $\begin{array}{l}\text { "Paced Educa- } \\
\text { tion" }\end{array}$ & $\begin{array}{l}\text { This model is designed to improve aca- } \\
\text { demic exploration by rigorously pushing } \\
\text { within disciplines. It has three distinct } \\
\text { phases: } \\
\text { Calibration } \\
\text { Elevation } \\
\text { Activation }\end{array}$ & $\begin{array}{l}\text { Moving from the four-year educational system } \\
\text { to three phases namely: Calibration, Eleva- } \\
\text { tion, and Activation. } \\
\text { Better choices can be made by students on } \\
\text { what to study. Also, this leads to mastery of } \\
\text { what students learned and how it was learned. } \\
\text { Calibration of micro-courses was developed } \\
\text { by the institution to identify potential students } \\
\text { for their elevation phase. } \\
\text { Creation of new spaces for reflection and a } \\
\text { rigorous student-professor learning period. } \\
\text { "Taste, try, reflect, achieve, fail, reflect, pur- } \\
\text { sue, succeed, apply, apply, apply. then again: } \\
\text { this was the experience of a Stanford student } \\
\text { in the era of Paced education." }\end{array}$ \\
\hline "Axis Flip" & $\begin{array}{l}\text { Students will master skills and } \\
\text { competence that will become the building } \\
\text { blocks of knowledge that can be rear- } \\
\text { ranged and translated across varying disci- } \\
\text { plines throughout their careers. Emphasis } \\
\text { is placed on rigor and transferable skills to } \\
\text { synthesize and navigate through the } \\
\text { growing world of information technology }\end{array}$ & $\begin{array}{l}\text { Stanford } 2025 \text { employed axis flip to flip } \\
\text { knowledge and competence axes so that skills } \\
\text { become an independent variable of educa- } \\
\text { tional institutions. } \\
\text { In the rapidly changing larbour market land- } \\
\text { scape, students are giving the opportunity to } \\
\text { have the basic idea in tackling career choice. } \\
\text { Ground-breaking research collaborations are } \\
\text { spiked by faculty accelerated at residence in } \\
\text { teaching hubs. } \\
\text { Skill-prints are used instead of transcripts. }\end{array}$ \\
\hline $\begin{array}{l}\text { "Purpose } \\
\text { Learning" }\end{array}$ & $\begin{array}{l}\text { The purpose of this model is not based on } \\
\text { career trajectory, but on the reason behind } \\
\text { it. This will be achieved by helping a stu- } \\
\text { dent choose a meaningful course of study } \\
\text { while in the educational institution and } \\
\text { then scaffold a better arc for the first } 10-15 \\
\text { years of the career. }\end{array}$ & $\begin{array}{l}\text { Graduates are accelerated by the outward } \\
\text { global impact and personal sense of meaning } \\
\text { for making career choices. } \\
\text { A list of endless research contributions to } \\
\text { resolve issues related to health, renewable } \\
\text { energy, global warming, governance, } \\
\text { infrastructure and cultural achievement. }\end{array}$ \\
\hline
\end{tabular}

Table 2. describes how Stanford2025 will be significant to educational institutions using the four proposed models to ease learning, as well as to diversify the scope of educating a competent and skilled workforce. However, computer-supported 
cooperative and collaborative learning (CSCL) has long been established as a medium that supports work-related and self-driven learning, following the idea of CTE and Stanford2025 projects. CSCL can help these learning approaches move to a new level. CSCL allows every student to have the opportunity to experiment physically with real equipment without necessarily being present at the location where the event is taking place.[29].

Before delving into student learning experience using computer aided systems, it is pertinent to understand how teaching also can be effectively delivered to students with the help of intelligent machines to support real-time teaching and learning.

\subsection{Orchestration of real-time classroom to support teaching and learning}

With regards to professional development of converging educational institution in the 4IR, many studies focus on a training format like Learning Management Systems, CD or Online [30], [31],[32]. LMS gives educational institutions the opportunity to deliver training effectively by the creation of student groups, mentoring and support communities. It is important for institutions to consider the best online practices for creating meaningful professional development activities, such as teaching [31].

Technology enhanced learning (TEL) liberates teachers from the daunting task of administrative and bureaucratic responsibilities by helping them to automate mundane paperwork. This is possible by employing AI techniques, thereby allowing teachers to concentrate on their main duties, which are teaching, conducting research and mentoring of students [33]. Over the last 30 years, research has shown that effective, individually tailored approaches can be achieved using Artificial Intelligence techniques and Intelligent Learning Environments (ILE).

The concept of an educational system that can be personalized and individualized has become ever more influential in recent times, especially in developed countries. Over the last few decades, research has shown the effectiveness of Artificial

Intelligence, Ubiquitous computing, IoT in Intelligent Learning Environments [33]. ILE are special TEL systems that are designed to produce an adaptive and interactive learning experience. These systems include tactical training systems and intelligent tutoring systems, like the 'ASSISTment' platform [34].

The most widely used ILE in formal education is the Learning Management Systems (LMS) which helps organize course content and administration by providing quizzes, puzzles, grades and forums for instructors to manage courses [31]. Popular open source applications of LMS are shown in Figure 2. 


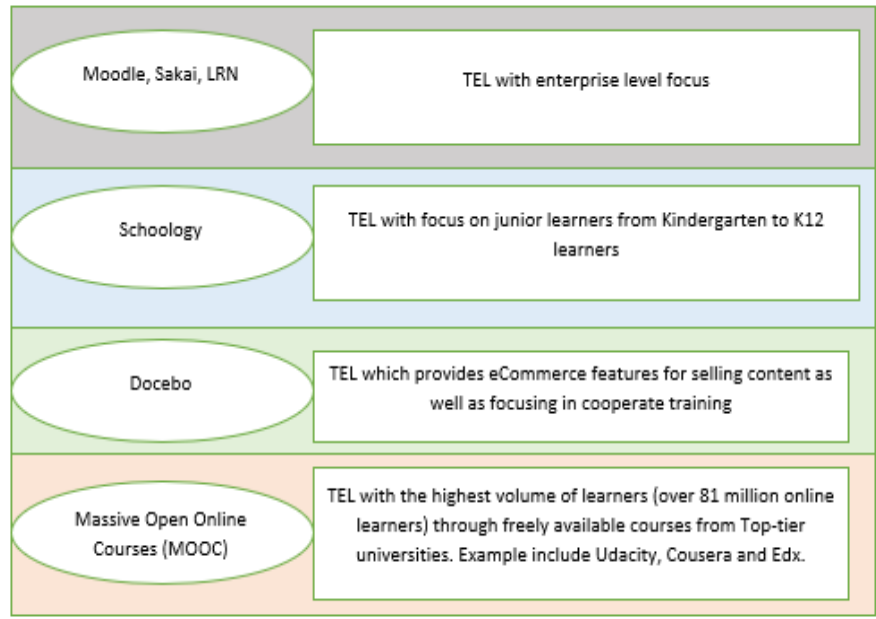

Fig. 3. TEL environments with focus area

Figure 2. shows TEL environments and their main area of focus. However, it is to be noted that most of the MOOC platforms, like Cousera, EdX and Audacity, have strong AI influence, either by research background or content featured [31], [35].

Massive open online courses (MOOC): MOOC leverages varying approaches to shape the role that can be overtaken by educational institutions in the 4IR. The combined strength of the traditional educational system with MOOCs represents measures needed to scale-up quality educational institutions in the 4IR. According to the World Economic Forum (WEF), the "Global Identity" and "Education for You" concept can be applied to MOOCs. This simply implies that, if an idea is globally embraced, it would transform global higher education [11].

A progressive practice of MOOC was presented in [36], and its impact was introduced in four universities and colleges curricula. Based on Big Data applications, MOOC platforms can assess student learning level dynamically. This can be achieved by enabling teachers to adjust and pace their teaching methodology. Furthermore, with the help and use of professional software and pocket labs, the best teaching effects can be achieved by MOOC when students master communication and innovation in engineering education.

Another study by [37], combines the experience of years in curriculum reforms with the integration of MOOC and flipped classroom in teaching Human Morphology. It probes the effects of teaching the flipped classroom based on MOOC courses. The author proposed a new method that conforms to the Medical Education curriculum and provides study references to explore teaching reforms based on talent training courses.

The idea of integrating MOOC with Small Private Open Course(SPOC) in the era of big data is a reversed classroom teaching mode proposed in [38]. It deals with challenges faced in traditional classroom teaching by enriching teachers with an enhanced medium for student participation inside and outside the classroom. It helps in cultivating the ability of students' self-learning using processes from teaching 
preparation, activities, implementations and evaluation before class in a mode-based on "MOOC+SPOC.". This model has received good student feedback and has improved teaching, which has built student enthusiasm by cultivating comprehension ability.

[39] A graduate-level sub-sample of students was examined in a blended MOOC that required completion of a campus course as a learning objective. The aggregate activity frequencies, order of activities and specific course item frequencies were used to predict the performance of students employing process mining, multiple regression and correlation. All MOOC aggregated activity frequencies indicate positive relationship in the on-campus examination grade, but the relationship is less informative when controlling for previous performance. In total, $65 \%$ of the specific course items showed a significant relationship with the final examination grades. Students who passed the course spread learning over more days, compared to students who did not pass the course. Evaluated results were combined with identified course points to improve MOOC. Encouragingly for the future workforce, "the boundaries between public and private, presence and absence, online and offline, material and immaterial have begun to dissolve"[40]. Therefore, the need to educate students, using a virtual environment to break the boundaries of absence of materials, experts, students, place or thing, could be resolved with the help of computer aided technology.

Efficacy of social robots and intelligent agent in educational institutions: The efficacy of intelligent agents and social robots in education is of primary interest in recent times. The outcomes of leveraging these machines in education will be discussed in this section. The main aim is to provide an overview of the significant impacts that might be expected when using an intelligent agent or social robots, compared with other control conditions, in varying educational scenarios with different factors among studies.

A brief review was conducted by [41] on the different types of robot designs used in pedagogy implementation and education research. This was based on four main criteria; forms, interaction capability and sensors, actuation and mobility. With regard to educational fields, robots can be of different forms, like pet or humanoid like forms.

Though, robots vary in functionalities, sizes and shapes, there are some common features, which encourage users to interact with robots, as most social robots must have a pleasing appearance. This is solely aimed at encouraging user interaction with robot, especially young users from kindergarten and primary schools. They all have processors embedded in them that are connected to the wireless Internet. This helps robots search for information when needed. They also possess two perception modes to interact with human beings. Many robots can perform facial and voice recognition to express emotions. Pet robots dominate the educational context, even though the biped humanoid robots have more applications. Perhaps, this may be due to reliability and safety concerns.

[42] conducted a survey on the attitudes of 59 German schoolteachers towards adopting educational robots and robot-mediated learning processes. The result was that teachers held a negative attitude about educational robots. The authors also found a positive relationship between the commitment to technology and teachers' attitudes towards robots in courses related to science, technology, engineering, and mathematics (STEM). With respect to the future use of robots in education, teachers preferred the 
use of education robots due to their easy handling or value as an information source. The main concerns of teachers were disruption of teaching processes, additional workload, or the fear that robots might replace interpersonal relationships. Implications of the findings for theory and design of education robots are discussed.

However, social robots are typically deployed in restricted scenarios: short, welldefined lessons, delivered with limited adaptation to individual learners or flexibility in curriculum. There is no suggestion yet that robots have the capability to tutor in a general sense as well as a human can. Comparisons between robots and humans are rare in the literature; so, no meta-analysis data were available to compare the cognitive learning effect size [43], [44].

Moving from social robots to intelligent agents, a study by [45] has developed an interactive virtual world, which provides educational features, based on simulation learning, animated pedagogical agents, and intelligent tutoring systems. Since most of the existing intelligent agents have limited capabilities, this study proposed to build a single agent with broader range of functions, such as spoken dialogue and cognitive reasoning. The aim of the study was to create a pathway for more sophisticated animated pedagogical agents with better applications in interdependence understanding and reasoning capabilities. Nevertheless, many intelligent agents, with more sophisticated capabilities, have been developed in recent times. Within the scope of artificial intelligence using the Natural Language Processing, appropriate questions can be aptly computerized, and the response will come through a Personal Digital Assistant (PDA) and an Intelligent Personal Assistant (IPA).

With regards to IPA, a study by [46] made use of IPAs ("Siri, Now, Cortana and Alexa") to reveal how and to what extent these devices might be utilized for learning, as well as for human-computer interaction (also known as Intelligent Pedagogical Agents) [47]. It was suggested that both devices (PDAs) and applications (IPAs) might be feasible tools for language learning; so more qualitative and quantitative studies may be conducted accordingly.

\section{Addressing the challenges of restructuring educational institutions for growth in the 4IR}

\subsection{Restructuring educational systems}

The World Economic Forum (WEF) estimated that $65 \%$ of pupils entering primary school today will ultimately work in jobs that are currently not in existence. Many novel cross-functional roles will be created with the 4IR for which employees will need the technical know-how, as well as social and analytical skills and competence to fit into these roles. Most existing institutions provide siloed education and continue several 20th century practices that are hindering the progress and performance of today's labour market. The main issue burdening the existing educational system is the dichotomy between training pupils in the humanities and applied science. Another challenge is the prestige attached to college degrees, rather than to the actual process of learning and the actual knowledge gained from learning. There is no good reason why these practices 
should be indefinitely maintained in today's world. Organizations, both private and public, should collaborate with educational institutions to reshape the school academic curriculum to mesh with organizational needs (Working World 4.0 or the 21 st curriculum) [11].

\subsection{Incentivizing lifelong learning}

To upskill and reskill, employees throughout life, or working cycles, ageing countries need to re-invest time in collaborating with business owners and government for opportunities that ensure the motivation of individuals. This implies that there is a need to reform the existing educational system to better equip students with future skills. At the government level, funds should be allocated to train adult workers every year. This will improve productivity and increase skilled workers in every discipline, with age not to be considered to be a barrier to the acquisition of skills.

\subsection{Grand challenges for artificial intelligence (AI) in education}

Changes to educational institutions to meet the 4IR requires the use of advance technological approaches, such as AI. Moreover, the educational system must AI to address such issues as:

- How to improve on virtual mentors for learners: Omnipresent support that integrates user modelling, social simulation and knowledge representation.

- Addressing 4IR skillset: Assist learners with self-direction, self-assessment, and teamwork.

- Analysis of interaction data: Bring together the vast amounts of data about individual learning, social and learning contexts and personal interests.

- Providing opportunities for connected classrooms: Increase the interconnectedness and accessibility of classrooms worldwide.

- Taking learning outside the boarders of classrooms: Learning should infuse all facets of a student's life.

\section{Conclusion with Future Study Recommendations}

Higher education is embracing changes. This openness to new ideas is increasingly essential for better understanding and the performance of students. Similarly, the changes ahead must also be considered in order to ensure effective and immediate restructuring of educational institutions. Educational institutions need to decide the strategic approach to utilize with their valuable experience in identifying new services. Henceforth, educational systems must be less risk averse, especially in the era of 4IR. There is no need to keep doing things the old-fashioned way. Acceptance of change and innovation is a must and is a prerequisite for skill acquisition and survival in a competitive environment. 
Another concern is the lack of access to digital education by people with marginal incomes and from developing countries (over four billion). These people still do not have access to internet, electric power, good water, or accessible roads. Educational institutions need to consider the best way of reaching the underserved populations where access to good education can serve as a strong tool for empowerment, prosperity and change.

\section{$5 \quad$ References}

[1] W. S. Bainbridge and M. C. Roco, "Science and technology convergence: with emphasis for nanotechnology-inspired convergence," J. Nanoparticle Res., vol. 18, no. 7, 2016. https://doi.org/10.1007/s11051-016-3520-0

[2] I. Lee and K. Lee, "The Internet of Things (IoT): Applications, investments, and challenges for enterprises," Bus. Horiz., vol. 58, no. 4, pp. 431-440, 2015. https://doi.org/ 10.1016/j.bushor.2015.03.008

[3] N. W. Gleason, Higher Education in the Era of the Fourth Industrial Revolution. 2018.

[4] B. Xing and T. Marwala, "Implications of the Fourth Industrial Age on Higher Education Bo Xing and Tshilidzi Marwala," arXiv Prepr. arXiv, no. April, pp. 2-9, 2006. https:// doi.org/10.25073/0866-773x/87

[5] A. Richert, M. Shehadeh, L. Plumanns, K. Gros, K. Schuster, and S. Jeschke, "Educating engineers for industry 4.0: Virtual worlds and human-robot-teams," Proc. IEEE Glob. Eng. Educ. Conf., no. April, pp. 142-149, 2016. https://doi.org/10.1109/educon.2016.7474545

[6] A. Basholli, T. Lagkas, P. A. Bath, and G. Eleftherakis, "Feasibility of sensor-based technology for monitoring health in developing countries-cost analysis and user perception aspects," pp. 1-12, 2015.

[7] D. Adjeroh, Pattern Matching in Compressed Texts and Images, vol. 6, no. 2-3. 2013.

[8] A. Selamat, Rose Alinda Alias, Syed Norris Hikmi, Marlia Puteh, and Siti Hamisah Tapsir, "Higher Education 4 . 0: Current Status and Readiness in Meeting the Fourth Industrial Revolution," Minist. High. Educ. Malaysia, no. August, pp. 23-24, 2017.

[9] W. Naudé, "Entrepreneurship , Education and the Fourth Industrial Revolution in Africa," IZA Discuss. Pap. No. 10855, no. 10855, pp. 1-25, 2017.

[10] K. Schuster, K. Groß, R. Vossen, A. Richert, and S. Jeschke, "Preparing for Industry 4.0 Collaborative Virtual Learning Environments in Engineering Education," Eng. Educ. 4.0, pp. 477-487, 2016. https://doi.org/10.1007/978-3-319-46916-4_36

[11] World Economic Forum, "The Future of Jobs - Reports - World Economic Forum," Res. Rep., no. January, p. 12, 2016.

[12] M. Xu, J. M. David, and S. H. Kim, "The fourth industrial revolution: Opportunities and challenges," Int. J. Financ. Res., vol. 9, no. 2, pp. 90-95, 2018.

[13] I. Isenhardt, S. Jeschke, K. Henning, F. Hees, and T. Meisen, "VIRTUAL IMMERSIVE ENGINEERING EDUCATION Prof . Dr . Anja Richert IMA / ZLW \& IfU of RWTH Aachen Institute Cluster IMA / ZLW \& IfU," no. September, 2015. https://doi.org/10. 1007/978-3-642-23662-4_14

[14] S. Tirocchi, Collaborative Exploiting Teens 'Skills in the Classroom, no. April 2018. 2020.

[15] M. Alavi and D. E. Leidner, "Knowledge management systems: issues, challenges, and benefits," Commun. AIS, vol. 1, no. 7, pp. 1-37, 1999.

[16] S. O. Becker, E. Hornung, and L. Woessmann, "Education and catch-up in the industrial revolution," Am. Econ. J. Macroecon., vol. 3, no. 3, pp. 92-126, 2011. 
[17] N. W. Gleason, "Higher Education in the Era of the Fourth Industrial Revolution," High. Educ. Era Fourth Ind. Revolut., pp. 1-229, 2018. https://doi.org/10.1007/978-981-13-0194$\underline{0 \_9}$

[18] M. A. Gottfried and J. S. Plasman, "Linking the Timing of Career and Technical Education Coursetaking With High School Dropout and College-Going Behavior," Am. Educ. Res. J., vol. 55, no. 2, pp. 325-361, 2018. https://doi.org/10.3102/0002831217734805

[19] M. A. Gottfried and C. Sublett, "Does Applied STEM Course Taking Link to STEM Outcomes for High School Students With Learning Disabilities?," J. Learn. Disabil., vol. 51, no. 3, pp. 250-267, 2018. https://doi.org/10.1177/0022219417690356

[20] F. S. J. Smink, Strategies to Help Solve Our School Dropout Problem, vol. 53, no. 9. 2013.

[21] J. Tomasello and B. Brand, "How ESSA and IDEA Can Support College and Career Readiness for Students With Disabilities Considerations for States,” p. 29, 2018.

[22] J. J. Kemple and J. C. Snipes, "Career Academies: Impacts on Students' Engagement and Performance in High School," Rep. ED441075 200pp Mar 2000, no. 5, p. 200, 2000.

[23] J. H. Bishop and F. Mane, "The impacts of career-technical education on high school labor market success," Econ. Educ. Rev., vol. 23, no. 4, pp. 381-402, 2004. https://doi.org/10. 1016/j.econedurev.2004.04.001

[24] S. Ward, "the Impact of Shared Leadership on a Career and Technical Education Campus," vol. 13, no. 1, 2017.

[25] M. Gentry, S. J. Peters, and R. L. Mann, "Differeences of General and Talented Student's in CTE experiences," J. Adv. Acad., vol. 18, no. 3, pp. 372-401, 2007.

[26] K. Saeger, "Career and Technical Education: The solution for preparing today's youth for college and career," CTE J., vol. 5, no. 9, 2013.

[27] H. Fox and T. Education, "READINESS \& SUCCESS Center How Career and Technical Education Can Help Students Be College and Career Ready : A Primer," 2018.

[28] Y. Ge, J. Zhang, and H. Ran, "Exploration of Students' Ability Cultivation in Blended Teaching,” vol. 220, no. Eemt, pp. 42-45, 2018.

[29] C. Terkowsky, D. May, T. Haertel, and C. Pleul, "Experiential remote lab learning with eportfolios: Integrating tele-operated experiments into environments for reflective learning," 2012 15th Int. Conf. Interact. Collab. Learn. ICL 2012, 2012. https://doi.org/10.1109/icl. 2012.6402097

[30] D. Vanneste, B. Vermeulen, and A. Declercq, "Healthcare professionals' acceptance of BelRAI, a web-based system enabling person-centred recording and data sharing across care settings with interRAI instruments: A UTAUT analysis," BMC Med. Inform. Decis. Mak., vol. 13, no. 1, pp. 1-14, 2013. https://doi.org/10.1186/1472-6947-13-129

[31] M. Elliott, N. Rhoades, C. Jackson, and J. Mandernach, "Professional Development: Designing Initiatives to Meet the Needs of Online Faculty," J. Educ. Online, vol. 12, no. 1, pp. 160-188, 2015. https://doi.org/10.9743/jeo.2015.1.2

[32] J. Grabara and P. Bosun, "Consideration on Online Education in Romania," Int. Lett. Soc. Humanist. Sci., vol. 25, pp. 59-65, 2014.

[33] P. S. Mohammed and E. 'Nell' Watson, "Towards Inclusive Education in the Age of Artificial Intelligence: Perspectives, Challenges, and Opportunities,” pp. 17-37, 2019. https://doi.org/10.1007/978-981-13-8161-4_2

[34] N. T. Heffernan and C. L. Heffernan, "The ASSISTments ecosystem: Building a platform that brings scientists and teachers together for minimally invasive research on human learning and teaching," Int. J. Artif. Intell. Educ., vol. 24, no. 4, pp. 470-497, 2014. https://doi.org/10.1007/s40593-014-0024-x

[35] C. J. Bonk, "A Systematic Review of MOOC Research Methods and Topics : Comparing 2014-2016 and 2016-2017 Coursera Free MOOCs Face the Music,” pp. 1-16, 2018. 
[36] F. Dong, J. Liu, H. Liu, and S. Dai, “The Impact of MOOC E-learning on Communication Engineering," no. Icesame, pp. 1275-1279, 2016.

[37] J. Lee, C. Lim, and H. Kim, "Development of an instructional design model for flipped learning in higher education," Educ. Technol. Res. Dev., vol. 65, no. 2, pp. 427-453, 2017. https://doi.org/10.1007/s11423-016-9502-1

[38] Q. Huang and G. Chen, "Innovation Analysis of MOOC + SPOC Reversal Classroom Teaching Reform Model Based on Big Data Era," no. Ietrc, pp. 297-301, 2019.

[39] R. Conijn, A. Van den Beemt, and P. Cuijpers, "Predicting student performance in a blended MOOC," J. Comput. Assist. Learn., vol. 34, no. 5, pp. 615-628, 2018. https://doi.org/1 $\underline{0.1111 / \mathrm{jcal} .12270}$

[40] C. Burnett and G. Merchant, "The Challenge of 21 st-Century Literacies," J. Adolesc. Adult Lit., vol. 59, no. 3, pp. 271-274, 2015. https://doi.org/10.1002/jaal.482

[41] A. Causo, G. T. Vo, I. M. Chen, and S. H. Yeo, "Design of robots used as education companion and tutor," Mech. Mach. Sci., vol. 37, pp. 75-84, 2016. https://doi.org/10.1007/ 978-3-319-22368-1_8

[42] N. R.-S. authorFriederike Eyssel, "Robots in the Classroom: What Teachers Think About Teaching and Learning with Education Robots," Springer, Int. Conf. Soc. Robot., vol. 9979., pp. 671-680, 2016. https://doi.org/10.1007/978-3-319-47437-3_66

[43] C. M. Huang and B. Mutlu, "Learning-based modeling of multimodal behaviors for humanlike robots," ACM/IEEE Int. Conf. Human-Robot Interact., pp. 57-64, 2014. https://doi.org/10.1145/2559636.2559668

[44] B. S. Bloom, "The 2 Sigma Problem: The Search for Methods of Group Instruction as Effective as One-to-One Tutoring," Educ. Res., vol. 13, no. 6, pp. 4-16, 1984. https:// doi.org/10.3102/0013189x013006004

[45] J. Rickel, "Intelligent virtual agents for education and training: Opportunities and challenges," Lect. Notes Comput. Sci. (including Subser. Lect. Notes Artif. Intell. Lect. Notes Bioinformatics), vol. 2190, pp. 15-22, 2001. https://doi.org/10.1007/3-540-44812-8_2

[46] N. Goksel Canbek and M. E. Mutlu, "On the track of Artificial Intelligence: Learning with Intelligent Personal Assistants," Int. J. Hum. Sci., vol. 13, no. 1, p. 592, 2016.

[47] P. Garrido, F. J. Martinez, and C. Guetl, "Adding semantic web knowledge to Intelligent Personal Assistant Agents," CEUR Workshop Proc., vol. 687, pp. 1-12, 2010.

\section{Authors}

Byabazaire Yusuf, Ph.D. is a senior faculty member in the field of Instructional Technology at Universiti Utara Malaysia (UUM), Kedah, Malaysia. He completed his $\mathrm{PhD}$ in Instructional Technology at the University of Malaya, Malaysia in 2010. His areas of research interest include; technology integration in education and training, use of technology in special needs education, and library and information science. He is also the co-editor for Fast forwarding Higher Education Institutions for Global Challenges: Perspectives and Approaches (2016).

Lynne Masel Walters, Ph.D. is a Senior Associate Professor in the Department of Teaching, Learning and Culture at Texas A\&M University. Her teaching and research interests are in multicultural education and the ways to increase reflective and critical thinking and technological competence by pre-service teachers. She also teaches and studies the use of digital storytelling in K-16 classrooms. Dr. Walters received her doctoral degree from the University of Wisconsin-Madison. 
Paper - Restructuring Educational Institutions for Growth in the Fourth Industrial Revolution (4IR)...

Siti Nazuar Sailin, PhD. is a Senior Lecturer in the field of Educational Technology and a Coordinator of Postgraduate Diploma in Education Programme. She holds a PhD from Monash University, Australia and has 15 years of teaching experience in higher education. Her research interest include technology integration in education, blended learning, flipped classroom and digital immersive learning experience.

Article submitted 2019-10-11. Resubmitted 2019-11-17. Final acceptance 2019-11-19. Final version published as submitted by the authors. 